\title{
A peptidorhamnomannan from the mycelium of Pseudallescheria boydii is a potential diagnostic antigen of this emerging human pathogen
}

\author{
Marcia R. Pinto, ${ }^{1}$ Barbara Mulloy, ${ }^{2}$ Rosa M. T. Haido, ${ }^{3}$ Luiz R. Travassos ${ }^{4}$ \\ and Eliana Barreto Bergter ${ }^{1}$
}

Author for correspondence: Eliana Barreto Bergter. Tel: +55 21590 3093. Fax: + 55215608344. e-mail: immgbel@microbio.ufri.br

1 Instituto de Microbiologia, Universidade Federal do Rio de Janeiro, CCS, Bloco I, Ilha do Fundão, 21941970, Rio de Janeiro, RJ, Brazil

2 National Institute for Biological Standards and Control, Blanche Lane, South Mimms, Potters Bar, Hertfordshire EN6 3QG, UK

The ascomycete Pseudallescheria boydii is an emerging human pathogen frequently found in soil and polluted water. A peptidopolysaccharide antigen has been isolated from mycelial forms of $\boldsymbol{P}$. boydii, and characterized using chemical and immunological methods. Monosaccharide composition, methylation analysis, and ${ }^{1} \mathrm{H}$ - and ${ }^{13} \mathrm{C}$-NMR spectra indicated the presence of a rhamnomannan with a structure distinct from those of similar components isolated from other fungi, containing $\operatorname{Rhap}(1 \rightarrow 3)$ Rhap epitopes on side chains which may be linked $(1 \rightarrow 3)$ to $(1 \rightarrow 6)$-linked mannose. The peptidorhamnomannan from $P$. boydii reacted poorly with an antiserum raised against whole cells of Sporothrix schenckii and strongly with one against $P$. boydii hyphae. These characteristics and immunological differences suggest that this major rhamnose-containing antigen of $P$. boydii may be useful for the specific diagnosis of infections attributable to this fungus.

Keywords: fungal pathogen, mycelium, peptidopolysaccharide, ${ }^{1} \mathrm{H}$ - and ${ }^{13} \mathrm{C}$-nuclear magnetic resonance

\section{INTRODUCTION}

The ascomycete Pseudallescheria boydii is frequently found in soil and polluted water. Several types of pathogenicity have been associated with P. boydii. It is known to cause human white-grain mycetoma (Rippon, 1998) and it has recently emerged as an agent of systemic and disseminated mycoses (Berenguer et al., 1989). P. boydii resembles other fungal species in tissue specimens and is not easily distinguished from Aspergillus species. Antibody levels and skin tests may help diagnosis of these fungi, particularly if allergic disease is suspected (Lake et al., 1990).

Very few studies on the antigenic composition and the immune response elicited during infection by $P$. boydii have been reported. Soluble antigens in culture filtrates were isolated and separated by anion-exchange

Abbreviations: COSY, correlated spectroscopy; DEPT, distortionless enhancement by polarization transfer; PAS, periodic acid/Schiff; TSP, trimethylsilylpropionic acid sodium salt. chromatography; they consisted of $70-96 \%$ carbohydrate and 4-16\% protein (Lupan \& Cazin, 1976). No detailed chemical composition of these antigens has been established. Here we report the characterization of a peptidorhamnomannan from mycelial forms of $P$. boydii, using GC, methylation analysis, ${ }^{1} \mathrm{H}$ - and ${ }^{13} \mathrm{C}$ NMR spectroscopy, ELISA and immunofluorescence techniques, and comparison with Sporothrix schenckii, another pathogenic fungus that also synthesizes rhamnose-containing antigenic structures (Travassos et al., 1973; Mendonça et al., 1976; Lopes-Alves et al., 1994).

\section{METHODS}

Micro-organism and growth conditions. Pseudallescheria boydii, isolated from eumycotic mycetoma, was kindly supplied by Dr Bodo Wanke, Evandro Chagas Hospital, Instituto Oswaldo Cruz, Rio de Janeiro, Brazil. It was maintained in a medium containing $\left(\mathrm{g} \mathrm{l}^{-1}\right)$ : Difco peptone, 10 ; Difco yeast extract, 5; Difco agar, 20; glucose, 40 . Cells were grown on Sabouraud solid medium and inoculated into 
Erlenmeyer flasks $(500 \mathrm{ml})$ containing liquid Sabouraud medium $(200 \mathrm{ml})$ which was incubated for $7 \mathrm{~d}$ at $25^{\circ} \mathrm{C}$ with shaking. Cultures were then transferred to the same medium (3 $\mathrm{l}$ ) and further incubated for $7 \mathrm{~d}$ at the same temperature with shaking; the mycelium was filtered with filter paper, washed with distilled water and dried.

Extraction and fractionation of peptidopolysaccharides. Crude extracts were obtained by extraction of the mycelium with hot phosphate buffer $(50 \mathrm{mM}, \mathrm{pH} 7 \cdot 2)$, at $100{ }^{\circ} \mathrm{C}$ for $2 \mathrm{~h}$, and were then fractionated by Cetavlon precipitation, according to Lloyd (1970). The mother liquors from the first Cetavlon precipitation were adjusted to $\mathrm{pH} 8.8$ with sodium borate and the resulting precipitate recovered by centrifugation to give the major fraction. This fraction, after uncoupling Cetavlon from the complex with acetic acid, was dialysed and lyophilized.

Fractionation of the peptidopolysaccharides (fraction B) on DE-52. The pH 8.8 Cetavlon-precipitated material was dissolved in $0.02 \mathrm{M}$ sodium phosphate buffer, $\mathrm{pH} 6 \cdot 1$, and applied to a DE-52 column (Whatman, $9.0 \times 2 \mathrm{~cm}$ ). A discontinous gradient of $0 \cdot 1 \mathrm{M} \mathrm{NaCl}$ in $0 \cdot 02 \mathrm{M}$ sodium phosphate buffer to $1 \mathrm{M} \mathrm{NaCl}$ was used to fractionate the sample. Eluted fractions were monitored by $A_{280}$ for protein, and colorimetrically $\left(A_{490}\right)$ for carbohydrate (Dubois et al., 1956).

SDS-PAGE. Peptidopolysaccharides were solubilized at $100{ }^{\circ} \mathrm{C}$ for $5 \mathrm{~min}$ in $0.06 \mathrm{M}$ Tris/ $\mathrm{HCl}, \mathrm{pH} 6.8,2 \%$ (w/v) SDS, $10 \%$ $(\mathrm{v} / \mathrm{v})$ glycerol and $0.025 \%(\mathrm{w} / \mathrm{v})$ bromophenol blue under reducing conditions by adding $5 \%(\mathrm{w} / \mathrm{v}) 2$-mercaptoethanol immediately before use (Laemmli, 1970). Electrophoresis was performed in a $12 \%$ polyacrylamide separating gel using a Bio Rad Mini-Protean II electrophoresis system. Gels were stained for carbohydrate with the periodic acid/Schiff (PAS) reagent and for protein with Coomassie blue.

Analytical procedures. Total carbohydrate was determined by the phenol/sulfuric acid method (Dubois et al., 1956), protein by the Lowry method, phosphate by the procedure of Ames (1966), and hexosamine by the method of Belcher et al. (1954).

Component monosaccharides. Peptidopolysaccharides were hydrolysed with $3 \mathrm{M}$ trifluoroacetic acid at $100{ }^{\circ} \mathrm{C}$ for $3 \mathrm{~h}$; the resulting monosaccharides were analysed (a) by HPTLC in nbutanol/acetone/water (5:4:1, by vol.) (Ovodov et al., 1967) and $(b)$ as their alditol acetates, which were characterized and quantified by GC-MS (Sawardeker et al., 1965).

Methylation analysis. Peptidopolysaccharides were methylated by the lithium methyl sulfinyl carbanion method (Parente et al., 1985). The partially methylated derivatives were converted to the corresponding alditol acetates and were analysed by GC coupled to electron-impact mass spectrometry. The partially methylated alditol acetates were separated on a fused silica capillary column of OV-225 $(30 \times 0.25 \mathrm{~mm}$, i.d. $)$, programmed from 50 to $220^{\circ} \mathrm{C}$ at a rate of $50{ }^{\circ} \mathrm{C} \mathrm{m^{-1 }}$, then hold.

${ }^{1} \mathrm{H}$ - and ${ }^{13} \mathrm{C}$-NMR spectroscopy. ${ }^{1} \mathrm{H}-(500 \mathrm{MHz})$ and ${ }^{13} \mathrm{C}-$ (125 MHz) NMR spectra were recorded using a Varian Unit 500 spectrometer. Samples $(10 \mathrm{mg}$ ) were dissolved in $0.75 \mathrm{ml}$ $\mathrm{D}_{2} \mathrm{O}(99.96 \%)$ with trimethylsilylpropionic acid sodium salt (TSP) as internal reference. ${ }^{13} \mathrm{C}$ chemical shifts were determined taking as reference the rhamnose methyl signal at 18.4 p.p.m. (Gorin, 1981). The DEPT (distortionless enhancement by polarization transfer) spectrum was recorded using the manufacturer's software. A double-quantum-filtered, gradient-assisted, magnitude-mode COSY spectrum was recorded using the pulse sequence GMQCOSY supplied by the spectrometer manufacturer.
Immunoreactivity of $\boldsymbol{P}$. boydii peptidorhamnomannan. Rabbit sera against whole $P$. boydii hyphae and Sporothrix schenckii mycelium phase (strain 1099.18) were used in this study. They were analysed by a direct ELISA method (Voller et al., 1976). Wells of flat-bottomed polyvinyl microtitre plates (Hemobag) were coated with $100 \mu \mathrm{l}$ of a $10 \mu \mathrm{g} \mathrm{ml}^{-1}$ solution of $P$. boydii peptidopolysaccharide. They were subsequently treated with PBS-Tween $20(0 \cdot 1 \%)$ containing $2 \%$ BSA as blocking agent; this and all subsequent incubations were at $37^{\circ} \mathrm{C}$ for $1 \mathrm{~h}$, The hyperimmune rabbit serum was used at a dilution of $1 / 200$ to $1 / 1638400$, and antibody binding was also measured using goat anti-rabbit IgG conjugated to horseradish peroxidase. The chromogen used was $o$-phenylenediamine, added with $\mathrm{H}_{2} \mathrm{O}_{2}$. Other steps were carried out as described by Haido et al. (1998).

Immunofluorescence. Indirect immunofluorescence analysis was carried out according to Haido et al. (1998). Fixed mycelia and conidia ( $2 \%$ formaldehyde in methanol) from $P$. boydii were treated with rabbit anti-P. boydii serum at a dilution of $1: 50$ and incubated for $60 \mathrm{~min}$ at $37^{\circ} \mathrm{C}$ in a moist chamber. A pre-immune serum was used as control. After washing, fluorescein-isothiocyanate-conjugated goat anti-rabbit IgG diluted 1:50 in PBS (10 mM, pH 7.2) was added. The slides were incubated for $60 \mathrm{~min}$, washed and examined in a fluorescence microscope. For the inhibition tests, the rabbit anti-P. boydii serum diluted 1:50 was pre-incubated for 60 min at $37^{\circ} \mathrm{C}$ with an equal volume of 50 and $100 \mu \mathrm{g} \mathrm{ml}^{-1}$ peptidorhamnomannan from both $P$. boydii and $S$. schenckii (Lima \& Lopes-Bezerra, 1997; Penha \& Lopes-Bezerra, 2000) and with a peptidogalactomannan from Aspergillus fumigatus strain 2109 (Haido et al., 1998).

\section{RESULTS}

\section{Isolation and purification of $\boldsymbol{P}$. boydii peptidorhamnomannan}

The phosphate buffer extract of $P$. boydii mycelium (total carbohydrate $70 \%$; protein $15 \%$; yield $50 \mathrm{mg}$ per g dry weight of mycelium) was fractionated by stepwise precipitation with Cetavlon at $\mathrm{pH} 7 \cdot 0$ and Cetavlon/borate at $\mathrm{pH} 8.8$ (fraction B) as previously described (Haido et al., 1998). The pH 8.8 Cetavlon-

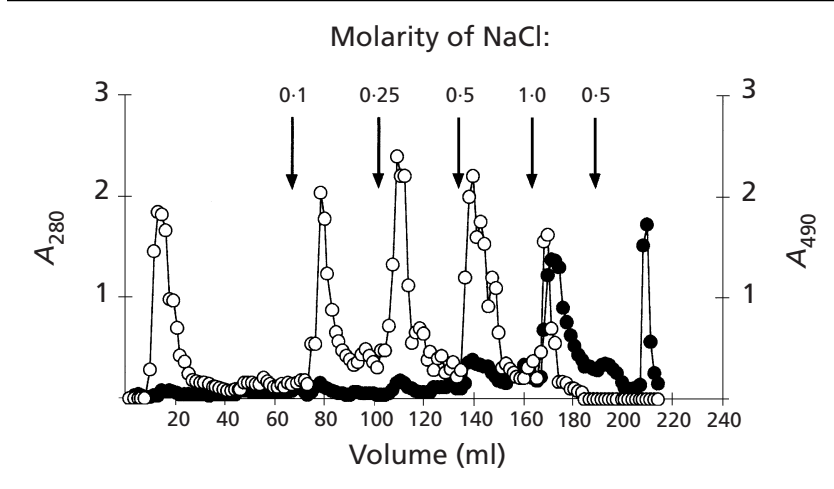

Fig. 1. Elution profile of the peptidopolysaccharides from $P$. boydii, fractionated by DE-52 column chromatography. Fraction $\mathrm{I}$ is the unbound fraction. Fractions II, III, IV and V were subsequently eluted with a discontinuous gradient of $\mathrm{NaCl}$ as shown. The last component was eluted with $0.5 \mathrm{M} \mathrm{NaOH}$. $\bigcirc$, Carbohydrate assayed colorimetrically $\left(A_{490}\right) ; 0$, protein determination by measuring $A_{280}$. 


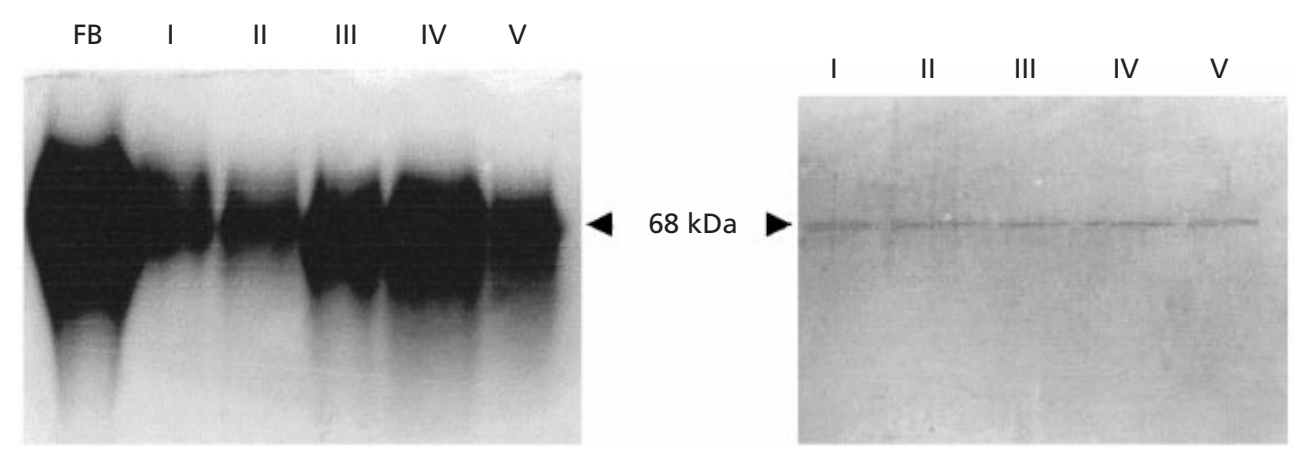

Fig. 2. SDS-PAGE of fraction $B(F B)$ from Cetavlon $\mathrm{pH} 8.8$ precipitation, and fractions I to $V$ from $D E-52$ fractionation of $P$. boydii peptidopolysaccharides. The diffusely migrating bands in the $50-80 \mathrm{kDa}$ range were stained by PAS (left panel). Protein staining by Coomassie blue of fractions I-V is shown in the right panel.

Table 1. Sugar component analysis of fractions $I-V$ of peptidopolysaccharides (fraction B) obtained by DE-52 column chromatography

Monosaccharides were analysed as their alditol acetate derivatives using a fused silica capillary column of OV-225 (30 m $\times 0 \cdot 25 \mathrm{~mm}$ i.d.) programmed from $50{ }^{\circ} \mathrm{C}$ to $220^{\circ} \mathrm{C}\left(50{ }^{\circ} \mathrm{C} \mathrm{min}^{-1}\right.$, then hold).

\begin{tabular}{|lcccc|}
\hline Fraction & \multicolumn{3}{c|}{ Monosaccharide composition (\%) } \\
\cline { 2 - 5 } & Rhamnose & Mannose & Galactose & Glucose \\
\hline B & $19 \cdot 5$ & $64 \cdot 0$ & $10 \cdot 0$ & $5 \cdot 5$ \\
I & $42 \cdot 5$ & $49 \cdot 5$ & $4 \cdot 5$ & $3 \cdot 5$ \\
II & $37 \cdot 0$ & $49 \cdot 0$ & $7 \cdot 0$ & $7 \cdot 0$ \\
III & $29 \cdot 5$ & $60 \cdot 5$ & $5 \cdot 5$ & $4 \cdot 5$ \\
IV & $36 \cdot 0$ & $54 \cdot 0$ & $5 \cdot 0$ & $5 \cdot 0$ \\
V & $40 \cdot 5$ & $47 \cdot 0$ & $6 \cdot 5$ & $6 \cdot 0$ \\
\hline
\end{tabular}

Table 2. GC-MS analysis of O-methylalditol acetates derived from methylation analysis of rhamnomannans of $P$. boydii

\begin{tabular}{|lcr|}
\hline Partially methylated alditol acetate & $\begin{array}{c}\text { Relative retention } \\
\text { time }\end{array}$ & $\begin{array}{c}\text { Area } \\
(\%)\end{array}$ \\
\hline 1,5-Di-O-acetyl-6-deoxy-2,3,4-tri-O-methylrhamnose & $0 \cdot 84$ & $12 \cdot 3$ \\
1,3,5-Tri-acetyl-6-deoxy-2,4-di-O-methylrhamnose & $0 \cdot 99$ & $12 \cdot 6$ \\
1,5-Di-O-acetyl-2,3,4,6-tetra-O-methylglucose & $1 \cdot 00$ & $2 \cdot 4$ \\
1,5-Di-O-acetyl-2,3,4,6-tetra-O-methylmannose & $1 \cdot 04$ & $13 \cdot 8$ \\
1,2,5-Tri-O-acetyl-3,4,6-tri-O-methylmannose & $1 \cdot 18$ & $17 \cdot 2$ \\
1,3,5-Tri-O-acetyl-2,4,6-tri-O-methylmannose & $1 \cdot 21$ & $10 \cdot 5$ \\
1,4,5-Tri-O-acetyl-2,3,6-tri-O-methylgalactose or glucose & $1 \cdot 25$ & $7 \cdot 5$ \\
1,5,6-Tri-O-acetyl-2,3,4-tri-O-methylmannose & $1 \cdot 27$ & $2 \cdot 3$ \\
1,3,4,5-Tetra-O-acetyl-2,6-di-O-methylmannose & $1 \cdot 41$ & $4 \cdot 7$ \\
1,2,5,6-Tetra-O-acetyl-3,4-di-O-methylmannose & $1 \cdot 66$ & $2 \cdot 4$ \\
1,3,5,6-Tetra-O-acetyl-2,4-di-O-methylmannose & $1 \cdot 68$ & $14 \cdot 2$ \\
\hline
\end{tabular}

precipitated material was further fractionated on a DE52 column. The unbound fraction (fraction I) was eluted with $0 \cdot 01 \mathrm{M}$ phosphate buffer, $\mathrm{pH} 6 \cdot 3$, and fractions II, III, IV and V were subsequently eluted with a dis- continuous $\mathrm{NaCl}$ gradient from $0 \cdot 1$ to $1 \mathrm{M}$ (Fig. 1). Further analyses were carried out using chiefly fraction III, which contained very little protein and had a high carbohydrate content. 
Table 3. Assignments of signals in the ${ }^{13} \mathrm{C}-\mathrm{NMR}$ spectrum of rhamnomannans from P. boydii

\begin{tabular}{|c|c|c|}
\hline \multicolumn{2}{|c|}{ Signal (p.p.m.) } & \multirow[t]{2}{*}{ Assignment } \\
\hline P. boydii* & $\begin{array}{c}\text { S. schenckii and } \\
\text { baker's yeast } \dagger\end{array}$ & \\
\hline $103 \cdot 6,103 \cdot 9$ & $103 \cdot 7$ & $\begin{array}{l}\text { C-1 of } \alpha \text {-D-Man } p \text { (non-reducing) end group and 3-O- } \\
\text { substituted residue }\end{array}$ \\
\hline $101 \cdot 7$ & $102 \cdot 0$ & C-1 of 2-O-substituted $\alpha$-D-Man $p$ residues \\
\hline $101 \cdot 2$ & $101 \cdot 1$ & C-1 of 3,6-di-O-substituted $\alpha$-D-Man $p$ residues \\
\hline $99 \cdot 6$ & $100 \cdot 3$ & C-1 of 2,6-di-O-substituted $\alpha$-D-Man $p$ residues \\
\hline $98 \cdot 2$ & $98 \cdot 2$ & $\begin{array}{l}\text { C-1 of } \alpha \text {-L-Rhap (non-reducing) end group of O- } \alpha \text {-L-Rhap- } \\
(1 \rightarrow 3) \text {-D-Man } p\end{array}$ \\
\hline $62 \cdot 8$ & $62 \cdot 8$ & C- 6 of unsubstituted $\alpha$-D-Man $p$ units \\
\hline $18 \cdot 4$ & $18 \cdot 4$ & C of methyl group of $\alpha-\mathrm{L}-\mathrm{Rhap}$ units \\
\hline
\end{tabular}

* Relative to the rhamnose methyl signal at $18 \cdot 4$ p.p.m.

†Taken from Travassos et al. (1974).
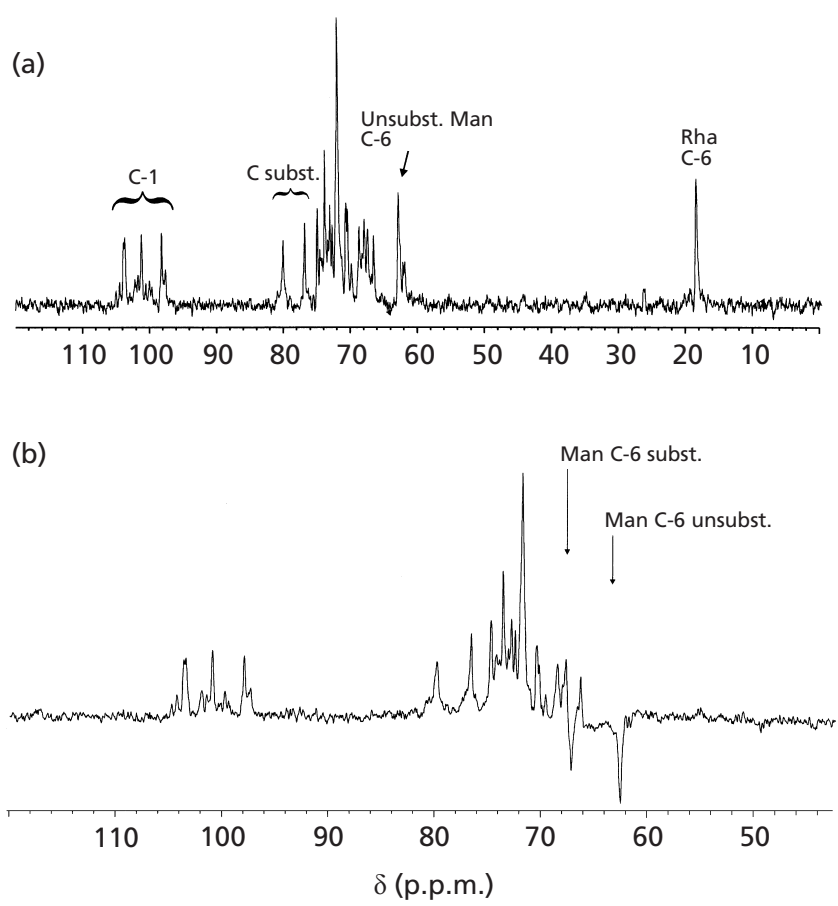

Fig. 3. (a) $125 \mathrm{MHz}{ }^{13} \mathrm{C}-\mathrm{NMR}$ spectrum of fraction III peptidopolysaccharides from $P$. boydii recorded at $60^{\circ} \mathrm{C}$ in $\mathrm{D}_{2} \mathrm{O}_{i}$ (b) DEPT ${ }^{13} \mathrm{C}-\mathrm{NMR}$ spectrum of the same molecules recorded at $45^{\circ} \mathrm{C}$ in $\mathrm{D}_{2} \mathrm{O}$. Chemical shifts are relative to rhamnose $\mathrm{C}-6$ at 18.4 p.p.m.

\section{SDS-PAGE}

Fraction $\mathrm{B}$ from Cetavlon $\mathrm{pH} 8.8$ precipitation, and the unbound and bound fractions from DE-52 chromatography, were subjected to SDS-PAGE under reducing conditions in a $12 \%$ linear polyacrylamide gel as described in Methods. A broad band was observed in all

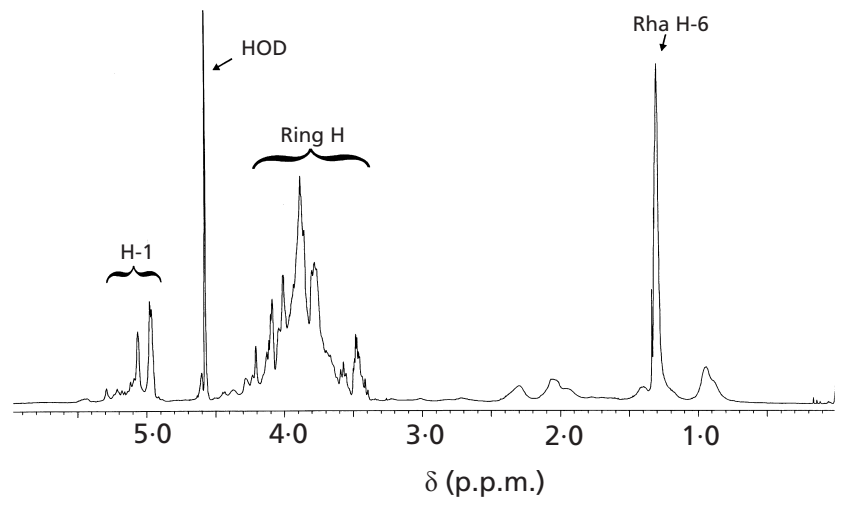

Fig. 4. $500 \mathrm{MHz}{ }^{1} \mathrm{H}-\mathrm{NMR}$ of fraction III peptidopolysaccharide from $P$. boydii recorded at $60^{\circ} \mathrm{C}$ in $\mathrm{D}_{2} \mathrm{O}$. Chemical shifts are relative to TSP at 0 p.p.m.

fractions, stained by PAS with apparent molecular mass in the $50-80 \mathrm{kDa}$ range (Fig. 2).

\section{Carbohydrate analysis of DE-52 column fractions}

The content of neutral carbohydrate in the DE-52 fractions is shown in Table 1. Predominant components were rhamnose and mannose, suggesting the presence of a rhamnomannan.

\section{Methylation analysis}

A peptidorhamnomannan-enriched fraction (fraction III eluted from the DE-52 column with $0.25 \mathrm{M} \mathrm{NaCl}$ ) was methylated, hydrolysed and the resulting units acetylated as described by Jansson et al. (1976). The O-methylalditol acetates are shown in Table 2.

Derivatives of 2,3,4-tri-O-methylrhamnose $(12 \cdot 3 \%)$ and 2,3,4,6-tetra-O-methylmannose $(13 \cdot 8 \%)$ originated from terminal rhamnose and mannose residues respectively. 


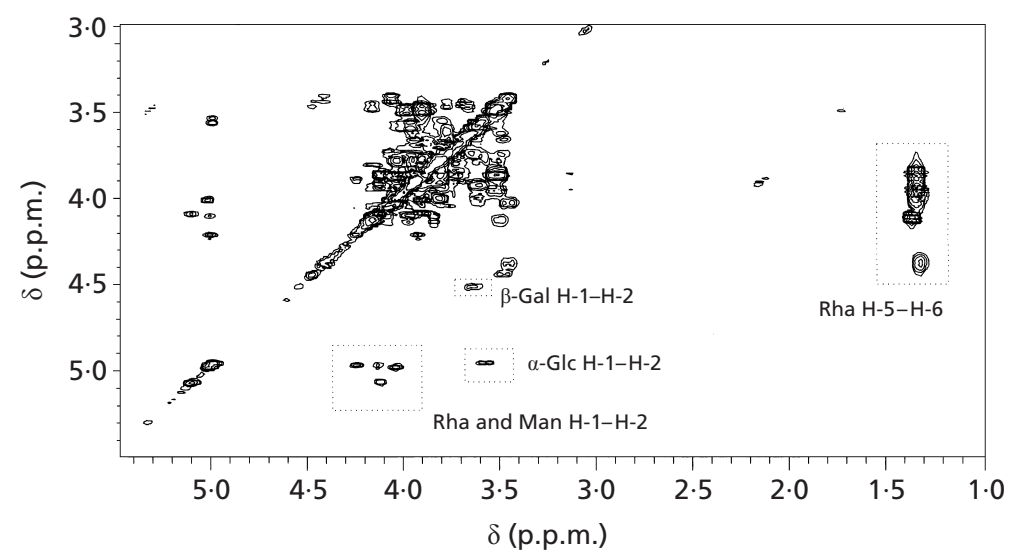

Fig. 5. Double-quantum-filtered, gradientassisted, magnitude-mode COSY spectrum of peptidopolysaccharide from $P$. boydii recorded at $45^{\circ} \mathrm{C}$ in $\mathrm{D}_{2} \mathrm{O}$. Cross-peaks and groups of cross-peaks for the well-resolved $\mathrm{H}-1-\mathrm{H}-2$ and $\mathrm{H}-5-\mathrm{H}-6$ signals are indicated by dotted boxes. The suggested assignments are tentative. Chemical shifts are relative to TSP at 0 p.p.m.

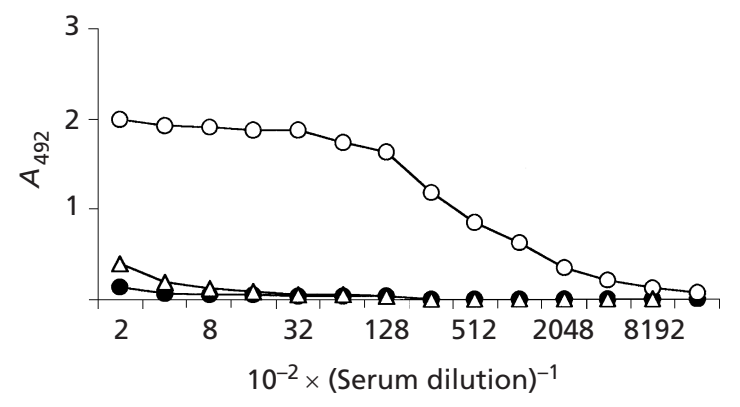

Fig. 6. Reactivity of $P$. boydii fraction III peptidopolysaccharide ( $1 \mu \mathrm{g}$ per well) with rabbit hyperimmune serum raised against whole mycelium of the fungus $(O)$, with anti-S. schenckii (strain 1099.18, mycelial phase) serum $(\triangle)$, and with pre-immune rabbit serum (๑). Serum dilutions were $1 / 200$ to $1 / 819200$.

Peaks corresponding to the derivatives of 2,4-diO-methylmannose $(14 \cdot 2 \%)$ and 2,3,4-tri-O-methylmannose $(2 \cdot 3 \%)$ suggest $\alpha$-(1 $\rightarrow 6)$-mannopyranosyl residues substituted at the 3 -positions by $\alpha$ rhamnopyranosyl-containing side chains. In Ceratocystis ulmi and S. schenckii (Travassos et al., 1973; Gorin \& Spencer, 1970) single rhamnosyl ramifications of the $\alpha$-(1 $\rightarrow 6)$-linked mannan were described. In $P$. boydii the presence of the 2,4-di-O-methylrhamnose derivative $(12.6 \%)$ suggests that the rhamnose side chains could be disaccharides with the structure $[\alpha-$ Rhap-(1 $\rightarrow 3)-\alpha$-Rhap-(1 $\rightarrow 3)$-] (Travassos et al., 1973). Methylation data additionally show that $(1 \rightarrow 2)$-linked mannose is also present $(17 \cdot 2 \%)$, with lesser amounts $(10.5 \%)$ of $(1 \rightarrow 3)$-substituted residues. Possibly the $(1 \rightarrow 2)$-linked mannosyl units are also located in side chains that have $\alpha$-mannosyl or $\alpha$-rhamnosyl terminal non-reducing units.

\section{NMR spectroscopy}

Well-resolved signals in the ${ }^{13} \mathrm{C}-\mathrm{NMR}$ spectrum of $P$. boydii are listed in Table 3, with values for similar compounds taken from Travassos et al. (1974) for comparison.

Anomeric resonances in the ${ }^{13} \mathrm{C}$ spectrum are consistent with the presence of mannose and rhamnose residues in several different environments. Signals at $103 \cdot 6$ p.p.m. and 103.9 p.p.m. are consistent with the presence of terminal and 3-O-linked mannose (Gorin, 1981). Other intense anomeric signals are at $101 \cdot 2$ p.p.m., consistent with C-1 of 3,6-di-O-substituted mannose (Travassos \& Lloyd, 1980) and at 98.2 p.p.m., consistent with nonreducing terminal rhamnose (Travassos \& Lloyd, 1980). A signal at 101.7 p.p.m. has a chemical shift near that reported for C-1 of 2-O-substituted mannose (Gorin, 1980) but is of lower intensity than would be predicted by methylation analysis. The ${ }^{13} \mathrm{C}-\mathrm{NMR}$ spectrum (Fig. 3a) also contains other minor anomeric signals. No anomeric signal was assigned to 3-linked rhamnose, one of the major components by methylation analysis.

A DEPT spectrum (Fig. 3b) has signals from carbons having two protons (in this case C-6 of Gal/Glc and Man residues) inverted. Two inverted signals can be easily identified, at $62 \cdot 8$ p.p.m. (typical of unsubstituted C-6) and at $67 \cdot 4$ p.p.m. (typical of substituted C-6).

${ }^{1} \mathrm{H}-\mathrm{NMR}$ spectroscopy of the peptidopolysaccharide (Fig. 4) reveals a strong spectrum originating from carbohydrate, with broad, weaker signals from the peptide. Distinctive signals arising from rhamnose H-6 methyl protons are seen at about 1.3 p.p.m.

A double-quantum-filtered, gradient-assisted, magnitude-mode COSY spectrum of the peptidopolysaccharide is shown in Fig. 5. Complete and definitive assignment of this spectrum is not possible due to severe signal overlapping, and broadening due to the high molecular mass of the peptidopolysaccharide. However, cross-peaks, and groups of cross-peaks for the wellresolved $\mathrm{H}-1-\mathrm{H}-2$ and rhamnose $\mathrm{H}-5-\mathrm{H}-6$ signals (identified by the distinctive high-field chemical shift of rhamnose $\mathrm{H}-6$ ) are indicated by dotted boxes. A group of signals from anomeric protons (H-1) appears between 4.9 and 5.5 p.p.m., and the COSY spectrum (Fig. 5) indicates that several corresponding $\mathrm{H}-2$ signals are found between 4.0 and 4.3 p.p.m., consistent with the presence of mannose and rhamnose. One H-1-H-2 cross-peak indicates an $\mathrm{H}-2$ signal at about 3.56 p.p.m., consistent with $\alpha$-glucose. The strong water (HOD) signal at 4.6 p.p.m. obscures the $\beta$-anomeric proton signal at about 4.5 p.p.m. with $\mathrm{H}-2$ at 3.62 p.p.m., consistent with a $\beta$-galactosyl unit. 

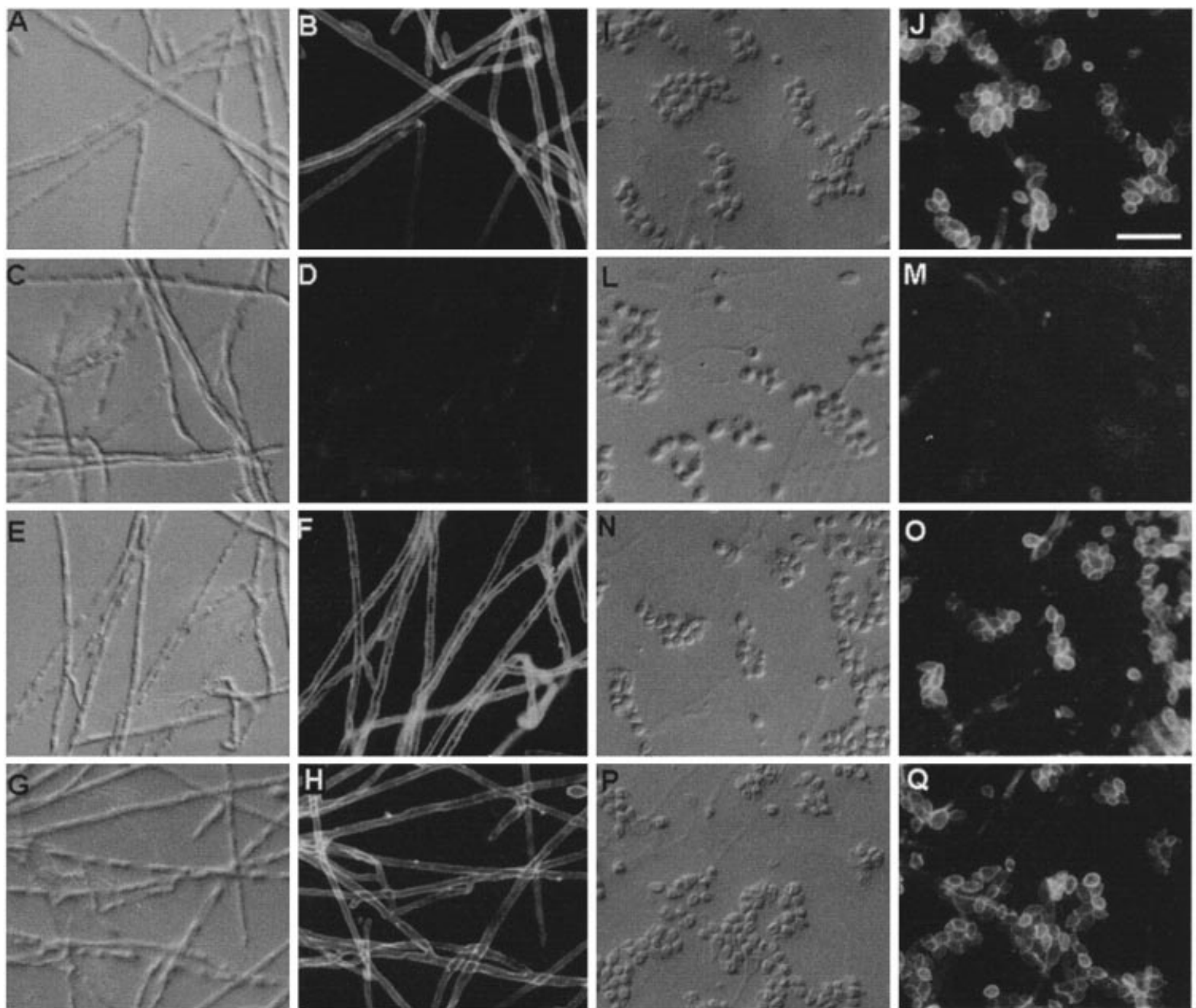

Fig. 7. Immunofluorescence of mycelium (B) and conidia (J) of $P$. boydii detected following incubation with rabbit antimycelium hyperimmune serum. Identical incubations were performed following pre-incubation of the serum with $P$. boydii fraction III peptidopolysaccharide $(\mathrm{D}, \mathrm{M})$, with $S$. schenckii peptidorhamnomannan $(\mathrm{F}, \mathrm{O})$ or with $A$. fumigatus peptidogalactomannan $(\mathrm{H}, \mathrm{Q})$ as described in Methods. Panels $\mathrm{A}, \mathrm{C}, \mathrm{E}, \mathrm{G}, \mathrm{I}, \mathrm{L}, \mathrm{N}$ and $\mathrm{P}$ show the same fields of $P$. boydii cells viewed by differential interferential contrast microscopy. Bar, $10 \mu \mathrm{m}$.

These tentative assignments of $\mathrm{H}-1-\mathrm{H}-2$ cross-peaks agree with the results of monosaccharide analysis (Table 1).

\section{Immunological reactivity of purified peptidorhamnomannan (fraction III)}

Fraction III was tested in ELISA using hyperimmune rabbit antisera against mycelial forms of both $P$. boydii and S. schenckii. P. boydii fraction III reacted strongly with the homologous antiserum whereas a much lower reactivity was obtained with the anti-S. schenckii serum (Fig. 6).

\section{Immunofluorescence}

The reactivity of the rabbit anti-P. boydii serum with hyphae and conidia of $P$. boydii, detected by indirect immunofluorescence, is shown in Fig. 7. A strong immunofluorescence reaction was observed with both cell types of this fungus, and the reaction was specifically inhibited by fraction III peptidorhamnomannan (Fig. 7). No reactivity was seen with the rabbit pre-immune serum (not shown). When the rabbit anti-P. boydii serum was incubated with a peptidorhamnomannan from $S$. schenckii or a peptidogalactomannan from $A$. fumigatus, no clear inhibition could be demonstrated (Fig. 7), suggesting the absence of cross-reactive determinants.

\section{DISCUSSION}

Rhamnomannans with traces of galactose or glucose, or both, have been identified in strains of Ceratocystis, Graphium and Hyalodendron pyrium (Travassos et al., 1974; Spencer \& Gorin, 1971). Among human-pathogenic fungi, however, rhamnomannans are seemingly restricted to Sporothrix schenckii (Travassos et al., 
1974). In the present work, the partial structure of a peptidorhamnomannan from $P$. boydii, an emergent human pathogen, was determined.

The family of peptidopolysaccharides from P. boydii which was fractionated by DE-52 column chromatography migrated in SDS-PAGE gels as a broad band in the $50-80 \mathrm{kDa}$ range, stained by both PAS and Coomassie blue. No other protein band appeared in the gel, which suggested that a defined group of closely related peptidopolysaccharides had been isolated. The degree of heterogeneity among these glycoconjugates was determined by the carbohydrate content and carbohydrate/protein ratios of the different fractions analysed in this work. Methylation analysis suggests that $\alpha$-L-Rha $p(1 \rightarrow 3)-\alpha$-L-Rha $p$ disaccharides are present in side chains, possibly linked $(1 \rightarrow 3)$ to $(1 \rightarrow 6)$ linked mannose residues. Mannose was also present as non-reducing end units, 2-O-, 3-O-, 6-O- and 2,4-di-Osubstituted units and a few 2,6- and 3,4-di-O-substituted units. The relatively high proportion of 2-O-substituted mannosyl units could be due to their inclusion in side chains with and without rhamnose, or the presence of O-linked mannosyl oligosaccharides in the glycoconjugate.

Methylation analysis identified several structures for which prominent signals would be expected in the ${ }^{13} \mathrm{C}$ NMR spectrum. Reasonable correspondence can be established between chemical shifts found in this study and literature values for several carbon signals in the anomeric and other well-resolved regions of the spectrum (Table 3). Unequivocal assignment of all NMR spectra awaits study of purified carbohydrate species from this rhamnomannan.

By comparison with the rhamnomannan extracted with hot dilute alkali from S. schenckii, Ceratocystis stenoceras and C. ulmi (Travassos et al., 1973; Gorin \& Spencer, 1970) it was evident that the rhamnomannan of $P$. boydii was significantly different. The dirhamnosyl side chains $-\alpha$-L-Rha $p(1 \rightarrow 2)-\alpha$-L-Rhap present in $S$. schenckii mycelial polysaccharides obtained at $25^{\circ} \mathrm{C}$ (Mendonça et al., 1976) were not found in the P. boydii rhamnomannan, which has $\alpha$-(1 $\rightarrow 3)$-linked rhamnosyl disaccharide.

The structural differences in the rhamnomannan of $P$. boydii as compared with a similar polysaccharide from S. schenckii, shown by methylation analysis, were confirmed by ${ }^{13} \mathrm{C}-\mathrm{NMR}$ spectroscopy. A consistent difference was the absence of signals at 96.8 p.p.m. and $80 \cdot 3$ p.p.m. corresponding respectively to the C-1 of $2-$ $O$-substituted $\alpha$-L-Rhap residues of $\alpha$-L-Rhap- $(1 \rightarrow 2)-\alpha$ Rhap and C-2 of 2-O-substituted $\alpha$-L-Rhap units (Travassos et al., 1974).

The ${ }^{1} \mathrm{H}-\mathrm{NMR}$ spectrum (Fig. 4), and the COSY spectrum (Fig. 5), with a limited number of clearly defined cross-peaks, is indicative of regularity in the carbohydrate structure; the peptide signals are too broad and too weak to give visible cross-peaks. Technical difficulties arise in obtaining a complete structural analysis by NMR of the whole peptidopolysaccharide, which has a high molecular mass and some degree of heterogeneity. However, studies of purified carbohydrate chains are currently being undertaken to determine their structures in detail.

Preliminary results on the nature of the antigenic determinants in $P$. boydii peptidorhamnomannan showed that fraction III contains antigenic determinants recognizable by anti-P. boydii antibodies, but that do not cross-react with anti-S.schenckii antibodies raised against whole cells of this fungus. This result can be explained on the basis of the immunodominance of the carbohydrate epitopes in the peptidorhamnomannans of both species. Lloyd \& Travassos (1975) showed that anti-S. schenckii antibodies reacted with $\beta$-L-Rhap- $(1 \rightarrow$ 3)- $\alpha$-D-Man $p$ but Lopes-Alves et al. (1994) later showed that a much stronger reactivity was obtained with the $\mathrm{O}$ linked chains containing 2-O- and 4-O-linked rhamnosyl units linked to $\alpha$-D-glucuronic acid. The very weak cross-reactivity between $P$. boydii and $S$. schenckii depends therefore on the low-titre anti- $\alpha$-L-Rhap $(1 \rightarrow$ 3) $\alpha$-D-Man $p$ antibodies, since the $\alpha$-L-Rha $p-(1 \rightarrow 3)-\alpha$-LRhap $(1 \rightarrow 3)$-L-Rhap-(1 $\rightarrow 3)-\alpha-\mathrm{D}-\mathrm{Man} p$ structure, with or without additional 2-O-linked mannopyranosyl units, appears to be unique to $P$. boydii.

By immunofluorescence we also showed that the rabbit antiserum against $P$. boydii mycelium strongly reacted with hyphae and conidia of this fungus, a reaction specifically inhibited by fraction III peptidorhamnomannan. A very weak inhibition was observed with the peptidorhamnomannan from S. schenckii (Penha \& Lopes-Bezerra, 2000) or a peptidogalactomannan from A. fumigatus (Haido et al., 1998).

To our knowledge, this is the first characterization of a chemically defined antigen from the mycelial forms of $P$. boydii. A major aim of this study was to determine whether this antigen could be useful for diagnostic purposes, mainly in mixed allergic bronchopulmonary fungal disease due to P. boydii and Aspergillus (Lake et al., 1990). The chemical characterization of fungal antigens is important to allow a rational interpretation of the cross-reactivity between pathogenic species, thus helping to select immunodominant components that can be of diagnostic use. The present work provides evidence for the expression of antigens which are similar but do not cross-react with $S$. schenckii peptidopolysaccharides and differ from the major Aspergillus glycoconjugate. Further studies are currently under way to determine the fine structure of the $P$. boydii antigen.

\section{ACKNOWLEDGEMENTS}

We thank Maria de Fatima F. Soares for technical assistance and Dr P. A. J. Gorin for the GC-MS analysis. This work was supported by grants from the Conselho Nacional de Desenvolvimento Cientifico e Tecnologico (CNPq), Financiadora de Estudos e Projetos (FINEP), Conselho de Ensino e Pesquisa da UFRJ (CEPG), Fundação de Amparo à Pesquisa do Estado do Rio de Janeiro (FAPERJ) and Programa de Núcleos de Excelência (PRONEX). 


\section{REFERENCES}

Ames, B. N. (1966). Assay of inorganic phosphate, total phosphate and phosphatases. Methods Enzymol 8, 115-118.

Belcher, R. A., Nutten, A. J. \& Sambrook, C. M. (1954). The determination of glucosamine. Analyst 79, 201-208.

Berenguer, J., Diaz-Mediavilla, J., Urra, D. \& Muñoz, P. (1989). Central nervous system infection caused by $P$. boydii: case report and review. Rev Infect Dis 11, 890-896.

Dubois, M., Gilles, K. A., Hamilton, J. K., Rebers, P. A. \& Swith, E. (1956). Colorimetric method for determination of sugar and related substances. Anal Chem 28, 350-356.

Gorin, P. A. J. (1981). Carbon-13 nuclear magnetic resonance spectroscopy of polysaccharides. Adv Carbohydr Chem Biochem 38, 13-104.

Gorin, P. A. J. \& Spencer, J. F. T. (1970). Structures of the Lrhamno D-mannan from Ceratocystis ulmi and the D-gluco-Dmannan from Ceratocystis brunnea. Carbohydr Res 13, 339-349.

Haido, R. M. T., Silva, M. H., Ejzemberg, R., Leitao, E. A., Hearn, V. M., Evans, E. G. V. \& Barreto Bergter, E. (1998). Analysis of peptidogalactomannan from the mycelial surface of Aspergillus fumigatus. J Med Mycol 36, 313-321.

Jansson, P. E., Kenne, L., Liedgren, H., Lindberg, B. \& Longen, J. (1976). A practical guide to the methylation analysis of carbohydrates. Chem Commun Univ Stockholm 8.

Laemmli, U. K. (1970). Cleavage of structural proteins during the assembly of the head of bacteriophage $\mathrm{T}_{4}$. Nature 227, 680-685.

Lake, F. R., Tribe, A. E., McAleer, R., Frondist, J. \& Thompson, P. J. (1990). Mixed allergic bronchopulmonary fungal disease due to Pseudallescheria boydii and Aspergillus. Thorax 45, 489-492.

Lima, O. C. \& Lopes-Bezerra, L. M. (1997). Identification of a Concanavalin A-binding antigen of the cell surface of Sporothrix schenckii. J Med Vet Mycol 35, 167-172.

Lloyd, K. O. (1970). Isolation, characterization and partial structure of peptidogalactomannan from the yeast form of Cladosporium wernecki. Biochemistry 9, 3446-3453.

Lloyd, K. O. \& Travassos, L. R. (1975). Immunochemical studies on L-rhamno-D-mannans of Sporothrix schenckii and related fungi by use of rabbit and human antisera. Carbohydr Res 40, 89-97.

Lopes-Alves, L., Travassos, L. R., Previato, J. O. \& MendonçaPreviato, L. (1994). Novel antigenic determinants from peptidorhamnomannans of Sporothrix schenckii. Glycobiology 4, 281-288.
Lupan, D. M. \& Cazin, J., Jr (1976). Serological diagnosis of petrillidiosis (allescheriosis). I. Isolation and characterization of soluble antigens from Allescheria boydii and Monosporium apiospermum. Mycopathologia 58, 31-38.

Mendonça, L., Gorin, P. A. J., Lloyd, K. O. \& Travassos, L. R. (1976). Polymorphism of $S$. schenckii surface polysaccharides as a function of morphological differentiation. Biochemistry 15, 2423-2431.

Ovodov, Y. S., Evtushenko, E. V., Vaskovsky, V. E., Ovodova, R. G. \& Soloveva, T. F. (1967). Thin layer chromatography of carbohydrates. J Chromatogr 26, 111-115.

Parente, J. P., Cardon, P., Leroy, Y., Montreuil, J., Fournet, B. \& Ricart, J. (1985). A convenient method for methylation of glycoprotein glycans in small amounts by using lithium methylsulfinyl-carbanion. Carbohydr Res 141, 41-47.

Penha, C. V. L. \& Lopes-Bezerra, L. M. (2000). Concanavalin Abinding antigens of Sporothrix schenckii: a serological study. Med Mycol 38, 1-7.

Rippon, J. W. (1998). Pseudallescheriasis. In Medical Mycology, 3rd edn, pp. 651-680. Philadelphia: W. B. Saunders.

Sawardeker, J. S., Sloneker, J. H. \& Jeanes, H. (1965). Quantitative determination of monosaccharides as their acetates by gas-liquid chromatography. Anal Chem 37, 1602-1604.

Spencer, J. T. F. \& Gorin, P. A. J. (1971). Systematics of the genera Ceratocystis and Graphium. Proton magnetic resonance spectra of the mannose-containing polysaccharides as an aid in classification. Mycologia 63, 387-402.

Travassos, L. R. \& Lloyd, K. (1980). Sporothrix schenckii and related species of Ceratocystis. Microbiol Rev 44, 683-721.

Travassos, L. R., Gorin, P. A. J. \& Lloyd, K. O. (1973). Comparison of the rhamnomannans from the human pathogen Sporothrix schenckii with those from the Ceratocystis species. Infect Immun 8, 685-693.

Travassos, L. R., Gorin, P. A. J. \& Lloyd, K. O. (1974). Discrimination between Sporothrix schenckii and Ceratocystis stenoceras rhamnomannans by proton and carbon-13 magnetic resonance spectroscopy. Infect Immun 9, 674-680.

Voller, A., Bidwell, D. \& Bartlett, A. (1976). Enzyme-linked immunosorbent assay. In Manual of Clinical Immunology, pp. 506-512. Edited by N. R. Rose \& H. M. Freidman. Washington, DC: American Society for Microbiology.

Received 17 October 2000; accepted 21 February 2001. 